\title{
Radical Scavenging Activity of the Essential Oil of Silver Fir (Abies alba)
}

\author{
Seun-Ah Yang1, Sang-Kyung Jeon², Eun-Jung Lee ${ }^{2}$, Nam-Kyung Im² $^{2}$, Kwang-Hwan Jhee ${ }^{3}$, \\ Sam-Pin Lee ${ }^{2}$, and In-Seon Lee ${ }^{2 * *}$ \\ ${ }^{1}$ The Center for Traditional Microorganism Resources, Keimyung University, Daegu 704-701, Korea \\ ${ }^{2}$ Department of Food Science and Technology, Keimyung University, Daegu 704-701, Korea \\ ${ }^{3}$ Department of Applied Chemistry, Kumoh National Institute of Technology, Gumi 730-701, Korea
}

Received 27 October, 2008; Accepted 27 November, 2008

\begin{abstract}
Summary The essential oil of silver fir (Abies alba) is known to help respiratory system and have easing and soothing effect for muscle. In the present study, we investigated the chemical composition, cytotoxicity and its biological activities of silver fir (Abies alba) essential oil. The composition of the oil was analyzed by GC-MS and bornyl acetate $(30.31 \%)$, camphene $(19.81 \%)$, 3-carene $(13.85 \%)$, tricyclene $(12.90 \%)$, dl-limonene $(7.50 \%)$, $\alpha$-pinene $(2.87 \%)$, caryophyllene $(2.18 \%)$, $\beta$-phellandrene $(2.13 \%)$, borneol $(1.74 \%)$, bicyclo[2.2.1]hept-2-ene,2,3dimethyl (1.64\%) and $\alpha$-terpinene $(1.24 \%)$ were the major components in the oil. The results tested by 3-(4,5-dimethylthiazol-2-yl)-2,5-diphenyl tetrazolium bromide (MTT) assay indicated that the oil showed no cytotoxic effect, at concentrations of 1 and 5\%, for as long as 24 and $3 \mathrm{~h}$, respectively. The antiradical capacity was evaluated by measuring the scavenging activity of the essential oil on the 2,20-diphenylpicrylhydrazyl (DPPH) and 2,2'-azino-bis 3-ethyl benzothiazoline-6-sulfonic acid (ABTS) radicals. The oil was able to reduce the both radicals dose-dependently, and the concentration required for $50 \%$ reduction $\left(\mathrm{RC}_{50}\right)$ against DPPH radicals $(2.7 \pm 0.63 \%)$ was lower than ABTS radicals $(8.5 \pm 0.27 \%)$. The antibacterial activity of the oil was also evaluated using disc diffusion method against Staphylococcus aureus, Streptococcus mutans, Listeria monocytogenes, Acinetobacter baumannii, Escherichia coli, and Vibrio parahaemolyticcus. The oil exhibited no antibacterial activity against all the bacterial strains tested except $S$. aureus of mild activity.
\end{abstract}

Key Words: silver fir essential oil, Abies alba, GC-MS, antiradical, antibacterial

\section{Introduction}

Essential oils obtained from various herbs are widely used in cosmetics and food manufacturing. Although there is a lack of clear scientific evidence for their effectiveness, the use of natural-essential oils as antioxidant or antiseptic has spread widely due to the increasing concern of the toxicity of synthetic additives. Because free radicals in food and in the

\footnotetext{
*To whom correspondence should be addressed

Tel: +82-53-580-6449 Fax: +82-53-580-6447

E-mail: inseon@kmu.ac.kr
}

human body have deleterious effects, natural sources of antioxidants are very important. It has been demonstrated that excessive formation of free radicals accelerates lipid oxidation in foods and decreases food quality [1]. Essential oils have been known to have various biological activity, especially antimicrobial and antioxidant capacity. For example, tea tree oil, one of the most popular essential oil recently, is widely known for its germicidal effect [2] and it is used for skin products, wound care, cosmetics and as natural antiseptic agents [3]. It also used as carminatives and in the treatment of several ailments [4] and essential oils including tea tree oil are found in many products like flavors, soaps, liniments, and dentistry products. Essential 
oils from lavender, peppermint, rosemary and lemon are also very popular and have been shown to have various biological capacities. Lavender oil exhibits anti-stress [5, 6], sedative, antimicrobial, and antioxidant effects [7, 8], and peppermint oil is used for the treatment of mental fatigue [9]. Essential oil of rosemary has been shown to stimulate the sympathetic nervous system and improve memory and concentration [10]. Citrus oils, such as lemon and grapefruit, are present in fruit flavors, and are mostly used as fragrances in foods and cosmetics throughout the world [11]. Essential oil of silver fir has also gained growing interest for its distinctive and refreshing pine-forest fragrance and it is known to help respiratory system and have easing and soothing effect for muscle. However, there is little information on the bioactivity of essential oil extracted from silver fir (Abies alba).

Thus, the present study investigated the biological activity such as cytotoxicity, chemical composition, antiradical and antibacterial activities of commercially available silver fir essential oil obtained from reliable company to get basic information about its potential for industrial application.

\section{Materials and Methods}

\section{Chemicals}

Pure standard substances of $\alpha$-pinene and $\gamma$-terpinene were purchased from Sigma-Aldrich (Sigma, St. Louis, MO) and limonene, $\beta$-pinene, $\alpha$-terpinene were from Tokyo Chemical Industry Co., Ltd. (TCI, Tokyo, Japan). Ascorbic acid was obtained from Shinyo chemical Co. Ltd. Butylated Hydroxytoluene (BHT), butylated Hydroxyanisole (BHA), 2,20-diphenylpicrylhydrazyl (DPPH), 2,2'-azino-bis 3-ethyl benzothiazoline-6-sulfonic acid (ABTS), Earle's basal salt solution (EBSS), trypsin solution, 3-(4,5-dimethylthiazol-2yl)-2,5-diphenyl tetrazolium bromide (MTT), trolox were obtained from Sigma Chemical Co. (St Louis, MO). Fetal bovine serum (FBS) and Dulbecco's modified eagle medium (DMEM) were from Gibco BRL (NY).

\section{Essential oil}

Commercial silver fir essential oil which extracted by steam distillation from leaf and twig of Abies alba (Pinaceae) was obtained from Skinmate (Puchon, Gyeonggi-do, Korea). It was stored in glass vials with Teflon sealed caps at $4^{\circ} \mathrm{C}$ in the absence of light.

\section{GC-MS analysis}

GC-MS spectrometry analysis of the oils was performed on a GC/MSD Polaris Q (Thermo Finnigan, TX) instrument. Briefly, HP5MS capillary column $(30 \mathrm{~m} \times 0.25 \mathrm{~mm}$ i.d., film thickness $0.32 \mu \mathrm{m}$ ) was used with the following temperature program: initial oven temperature, $40^{\circ} \mathrm{C}$ for $5 \mathrm{~min}$; then gradient of $4^{\circ} \mathrm{C} / \mathrm{min}$ to $200^{\circ} \mathrm{C}$, held $5 \mathrm{~min}$; followed by a gradient of $20^{\circ} \mathrm{C} / \mathrm{min}$ to $280^{\circ} \mathrm{C}$, held $10 \mathrm{~min}$. Injector line temperatures was set at $260^{\circ} \mathrm{C}$, and a split ratio of 10:1 was applied. Helium was used as the carrier gas at a flow rate of $1.0 \mathrm{ml} / \mathrm{min}$. The interface temperature was $280^{\circ} \mathrm{C}$. For GC-MS detection, electron ionization system with ionization system energy $70 \mathrm{eV}$ was used. Total ion current (TIC) chromatograms were recorded in a mass range of 30-350 amu. The components were identified by comparison of their relative retention times with authentic substances and mass spectra with NIST, WILLY library data of the GC-MS system and literature data.

\section{Cell culture and treatment}

Skin CCD-986SK human fibroblast cells were obtained from Korean cell line bank (Seoul, Korea). Cells were cultured at $37^{\circ} \mathrm{C}$ in the presence of $5 \% \mathrm{CO}_{2}$ in DMEM supplemented with $10 \%$ FBS. For the treatment, the oil was diluted with a culture medium. In every experiment, cells in negative control group were treated with the same concentration of dimethyl sulfoxide (DMSO) $(0.1 \%)$ as contained in the silver fir oil-treated group.

\section{Determination of cell viability}

Cell viability that was assessed by the MTT staining assay [12] based on the reduction of a MTT into formazan dye by active mitochondria reflects the cytotoxicity of silver fir oil. CCD-986SK cells were seeded at a density of 10,000 cells/well in 96-well microplate. The next day, cells were treated with the oil at $37^{\circ} \mathrm{C}$ for $48 \mathrm{~h}$. At the end of culture, $100 \mu \mathrm{l}$ of MTT $(5 \mathrm{mg} / \mathrm{ml})$ were added to each well, and plates were incubated at $37^{\circ} \mathrm{C}$ for $4 \mathrm{~h}$. One hundred microliters DMSO were added to each well to dissolve the cells. The plates were kept at room temperature for $5 \mathrm{~min}$ and the absorbance was measured at $550 \mathrm{~nm}$ using a multiwell spectrophotometer (Molecular Devices, Sunnyvale, CA).

\section{Bacterial cultures}

The $S$. aureus were grown in tryptic soy agar broth (Becton Dickinson, MD), and the S. mutant and L. monocytogenes were grown in brain heart infusion broth (Becton Dickinson, MD). Other bacteria strains were grown in nutrient broth (Becton Dickinson, MD) with aeration at $37^{\circ} \mathrm{C}$.

\section{Antibacterial screening}

The agar diffusion method was employed to determine the antibacterial activity of the essential oil [13]. Briefly, sterile 8-mm paper discs were individually impregnated with $25 \mu \mathrm{l}$ of the essential oil and placed on the solid media plates, which had been surface spread with the tested bacteria $\left(2 \times 10^{8} \mathrm{CFU} / \mathrm{ml}\right)$. Plates were incubated at $37^{\circ} \mathrm{C}$ for $24 \mathrm{~h}$ and the inhibition zones were measured against bacterial strains tested. 


\section{DPPH radical scavenging activity}

Radical scavenging activity was determined using DPPH as a free radical by the method described in the literature [14] with some modifications. This spectroscopic assay uses the stable radical DPPH as a reagent. Briefly, $200 \mu \mathrm{L}$ of various concentrations of sample was added to $50 \mu \mathrm{L}$ of DPPH solution $(0.15 \mathrm{mM}$ in methanol) in a 96-well microtiter plate. The sample was dissolved in methanol and used. After $30 \mathrm{~min}$ incubation in the dark at room temperature, the decrease in absorbance was measured at $517 \mathrm{~nm}$. Methanol was used as blank solution, and DPPH solution without the essential oil served as control. BHT, BHA, and ascorbic acid were used as synthetic references. Reduction of DPPH radical in percent $(R \%)$ was calculated in following way:

$$
R \%=\left(\mathrm{A}_{\text {blank }}-\mathrm{A}_{\text {sample }} / \mathrm{A}_{\text {blank }}\right) \times 100,
$$

where Ablank is the absorbance of the control reaction (containing all reagents except the test sample), and Asample is the absorbance of the test sample. Tests were carried out in triplicate. For the final results, $\mathrm{RC}_{50}$ values (the concentrations required for $50 \%$ reduction of DPPH $(0.15 \mathrm{mM})$ at $30 \mathrm{~min}$ after starting the reaction) were calculated from the absorbance diminished by $50 \%$. The experiment was performed in triplicate.

\section{ABTS radical scavenging activity}

The antiradical activity using ABTS was measured by ABTS cation decolorisation assay method, as described by Re et al. [15]. Briefly, ABTS radical cation was freshly prepared by mixing $14 \mathrm{mM}$ ABTS with an equal volume of $4.95 \mathrm{mM}$ potassium persulfate and kept for $24 \mathrm{~h}$ in dark at room temperature. This ABTS radical cation solution was used for the assay after dilution in phosphate buffer saline (PBS) appropriately. To $50 \mu \mathrm{l}$ of various concentration of sample, $150 \mu \mathrm{l}$ of ABTS radical solution was added. After $1 \mathrm{~min}$ incubation at room temperature, the absorbance was measured at $732 \mathrm{~nm}$. Methanol was used as blank solution, and ABTS solution without the essential oil served as control. Trolox was used as reference synthetic antioxidant compound. The experiment was performed triplicate. Reduction of ABTS radical in percent $(R \%)$ and $\mathrm{RC}_{50}$ value were calculated the same as described in DPPH radical assay.

\section{Statistical analysis}

All the experiments were performed three to five times. Data are expressed as the mean \pm standard error of the mean (SEM) or SD. A significant difference from the respective controls for each experimental test condition was assessed using Student's $t$ test for each paired experiment. A $p$-value of $<0.05$ was regarded as indicating a statistical significance.

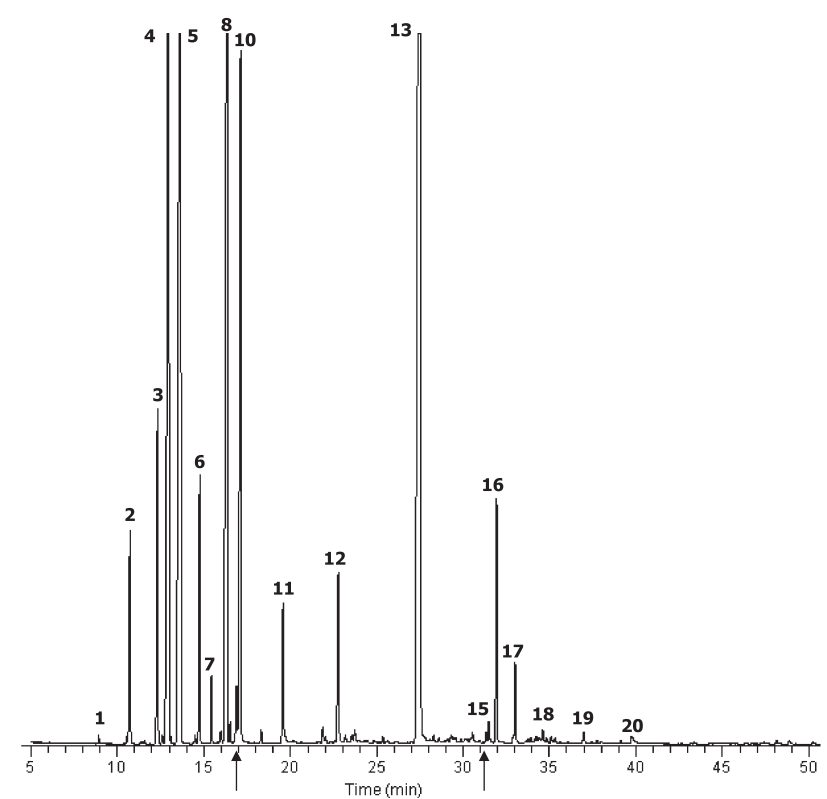

Fig. 1. Total ion current chromatograms of silver fir essential oil obtained by GC-MS analysis. The numbers refer to those in Table 1.

\section{Results and Discussion}

\section{Chemical composition of the essential oil}

Silver fir essential oil tested in this study was analyzed using GC-MS to identify its major components. Total ion chromatography of the oils revealed 20 significant peaks (Fig. 1). We analyzed the mass spectrum of each peak, followed by a search of the library of mass spectra of known chemicals. Authentic standard substances for its candidate were also analyzed using GC-MS under the same condition as in the oil analysis and the results were compared. The result of the silver fir oil is shown in Table 1 . The oil predominantly contained bornyl acetate (30.31\%), camphene $(19.81 \%)$, 3-carene $(13.85 \%)$, tricyclene $(12.90 \%)$, dllimonene (7.50\%), $\alpha$-pinene $(2.87 \%)$, caryophyllene (2.18\%), $\beta$-phellandrene $(2.13 \%)$, borneol (1.74\%), bicyclo [2.2.1]hept-2-ene,2,3-dimethyl (1.64\%) and $\alpha$-terpinene (1.24\%).

Silver fir essential oil has recently become popular for aromatherapy, however, little is known about its biological activities and composition. Zeneli et al. [16] have been reported that $\alpha$-pinene, camphene, $\beta$-pinene, limonene and bornyl acetate were the major component in the needle oleoresin, and $\alpha$-pinene, $\beta$-pinene, limonene, $\beta$ caryophyllene and germacrene $\mathrm{D}$ comprised the majority of cortical oleoresin of silver fir in Albania.

Effect of the essential oil on human fibroblast cell viability The result of cytotoxicity of the silver fir oil on the CCD- 
Table 1. Main components (\%) detected by GC-MS in the silver fir essential oil

\begin{tabular}{clcc}
\hline No. & \multicolumn{1}{c}{ Compound } & RT ${ }^{\text {a) }}(\mathrm{min})$ & Silver fir oil (\%) $^{\text {b }}$ \\
\hline 1 & 2-Pentanone,4-hydroxy-4-methyl- & 8.91 & 0.06 \\
2 & Bicyclo[2.2.1]hept-2-ene,2,3-dimethyl- & 10.72 & 1.64 \\
3 & $\alpha$-Pinene & 12.32 & 2.87 \\
4 & 3-Carene & 12.97 & 13.85 \\
5 & Camphene & 13.65 & 19.81 \\
6 & $\beta$-Phellandrene & 14.76 & 2.13 \\
7 & $\beta$-Pinene & 15.44 & 0.51 \\
8 & Tricyclene & 16.33 & 12.90 \\
9 & $p$-Cymene & 16.87 & 0.57 \\
10 & dl-Limonene & 17.12 & 7.50 \\
11 & $\alpha$-Terpinene & 19.56 & 1.24 \\
12 & Borneol & 22.75 & 1.74 \\
13 & Bornyl acetate & 27.50 & 30.31 \\
14 & Aromadendrene & 31.35 & 0.05 \\
15 & Humulene & 31.51 & 0.20 \\
16 & Caryophyllene & 31.97 & 2.18 \\
17 & $\beta$-Elemene & 33.03 & 0.72 \\
18 & Valencene & 34.62 & 0.13 \\
19 & Androstan-17-1,3-ethyl-3-hydroxy-,(5a)- & 37.00 & 0.12 \\
20 & $\alpha$-Bisabolene & 39.77 & 0.12 \\
\hline
\end{tabular}

a) Percentages obtained by MSD peak area normalization.

b) Retention time

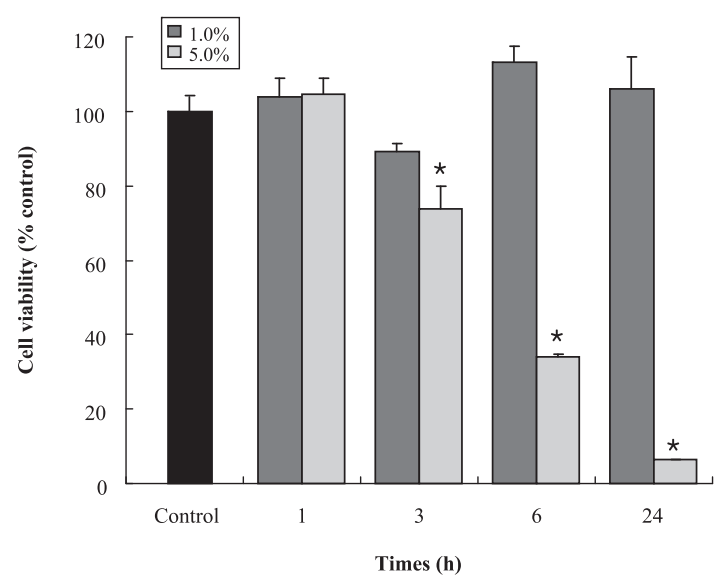

Fig. 2. Effects of silver fir oil on the viability of CCD-986SK human fibroblast cells. Cells were treated with the oil for 24 h. $* p<0.01$ compared to control.

986SK human fibroblast cells is shown in Fig. 2. The essential oil did not affect the cell viability for $24 \mathrm{~h}$ after the cell treatment at the lower oil concentration $(1.0 \%)$, although the high concentration of the oil $(5.0 \%)$ significantly decreased cell viability after $3 \mathrm{~h}$ treatment. The $5.0 \%$ oil dramatically decreased cell viability to $34.0 \pm 0.97 \%$ and $6.3 \pm 0.22 \%$ after 6 and $24 \mathrm{~h}$, respectably.

There is no data available on the cytotoxicity of silver fir oil to use human skin directly. The antiproliferative and anticarcinogenic effects of aqueous preparation of Abies alba and Viscum album se abies was investigated on benzopyrene-induced tumors in Wistar rats and on the L1210 malignant cell line by Karkabounas et al. [17].

\section{Free radical-scavenging activity}

Free radical-scavenging capacity was evaluated by measuring the scavenging activity of the essential oil on DPPH and ABTS radicals. DPPH radical scavenging activities of the silver fir oil and of references at $5 \mu \mathrm{g} / \mathrm{ml}$ are presented in Fig. 3(A). The essential oil reduced the DPPH radical formation in a dose-dependent manner. The scavenging activities of the oil were $16.3 \pm 3.22,22.8 \pm$ $5.26,38.6 \pm 2.37,80.0 \pm 6.82,93.6 \pm 1.54$ at $1.0,1.7,2.5$, $5.0,10.0 \%$ oil concentrations, respectively. Among the references at $5 \mu \mathrm{g} / \mathrm{ml}$, ascorbic acid $(96.5 \pm 2.31 \%)$ showed higher DPPH radical-scavenging activity than BHA (70.3 \pm $7.57 \%)$ or BHT $(20.2 \pm 0.92 \%)$, and it was almost equal to the $10.0 \%$ oil activity. Moreover, the radical scavenging activities of the oil (1.0 to $10.0 \%$ ) were comparable with or stronger than that of $5 \mu \mathrm{g} / \mathrm{ml}$ BHT. ABTS radical scavenging activity of the essential oil was also investigated with various oil concentrations. As shown in Fig. 3(B), the oil also reduced the ABTS radical formation in a concentrationdependent manner. The ABTS radical-scavenging activities 
(A)

(B)
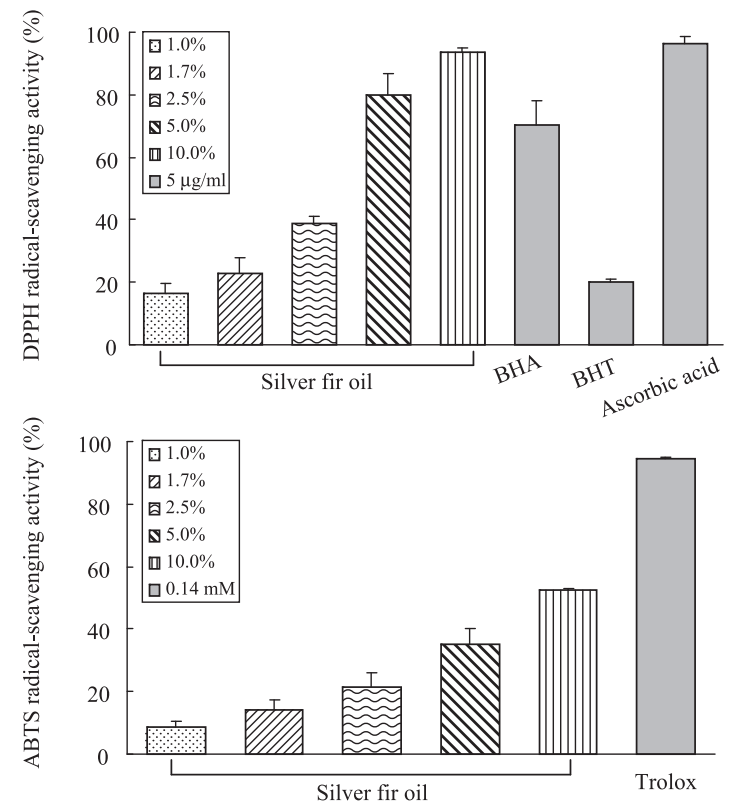

Fig. 3. Free radical-scavenging activities of silver fir essential oil and references. Essential oil was diluted in methanol to $1.0 \%, 1.7 \%, 2.5 \%, 5.0 \%, 10.0 \%$ and the references were used at $5 \mu \mathrm{g} / \mathrm{ml}$ for DPPH (A) and $0.14 \mathrm{mM}$ trolox for ABTS system (B).

Table 2. $\mathrm{RC}_{50}$ values of silver fir essential oil and reference antioxidants

\begin{tabular}{lcc}
\hline \multirow{2}{*}{ Sample $^{\text {b) }}$} & \multicolumn{2}{c}{ RC50 value (\%) $^{\text {a) }}$} \\
\cline { 2 - 3 } & DPPH scavenging & ABTS scavenging \\
\hline Silver fir oil & $2.7 \pm 0.63$ & $8.5 \pm 0.27$ \\
BHA $^{c)}(\mu \mathrm{g} / \mathrm{ml})$ & $3.7 \pm 0.60$ & - \\
BHT $^{c)}(\mu \mathrm{g} / \mathrm{ml})$ & $39.3 \pm 1.11$ & - \\
Ascorbic $\mathrm{acid}^{\text {c) }}(\mu \mathrm{g} / \mathrm{ml})$ & $2.0 \pm 0.13$ & - \\
$\operatorname{Trolox}^{\text {d) }}(\mu \mathrm{M})$ & - & $73.5 \pm 0.59$ \\
\hline
\end{tabular}

a) Concentration required for $50 \%$ reduction of DPPH $(0.15 \mathrm{mM})$ or ABTS $(7 \mathrm{mM})$ radicals

b) Values are means $\pm \operatorname{SEM}(n=5)$.

c) Standard compound for DPPH assay

d) Standard compound for ABTS assay

were $8.5 \pm 2.12, \quad 14.3 \pm 2.92, \quad 21.6 \pm 4.42, \quad 35.3 \pm 5.08$, $52.7 \pm 0.47$ at $1.0,1.7,2.5,5.0,10.0 \%$ oil concentrations, respectively and the oil showed less effective scavenging activity against ABTS radical than DPPH radical. The values of $\mathrm{RC}_{50}$ of the essential oil and the references against DPPH and ABTS radicals were determined as shown in Table 2. The silver fir essential oil exhibited slightly lower $\mathrm{RC}_{50}$ value against DPPH radicals $(2.7 \pm 0.63 \%)$ than ABTS radicals $(8.5 \pm 0.27 \%)$.

There is no data available about the antioxidant capacity
Table 3. Antibacterial effect of silver fir essential oil using disc diffusion method against bacterial strains

\begin{tabular}{lcc}
\hline \multirow{2}{*}{ Strain } & \multicolumn{2}{c}{ Clear zone $(\mathrm{mm})^{1)}$} \\
\cline { 2 - 3 } & Silver fir oil $^{2)}$ & Gentamicin $^{3)}$ \\
\hline A. baumannii & $8 \pm 0.0^{4)}$ & $12 \pm 0.6$ \\
E. coli & $9 \pm 0.1$ & $12 \pm 0.6$ \\
V. parahaemolyticcus & $8 \pm 0.0$ & $9 \pm 1.7$ \\
S. aureus & $17 \pm 0.1$ & $25 \pm 0.6$ \\
S. mutans & $8 \pm 0.1$ & $18 \pm 1.0$ \\
L. monocytogenes & $8 \pm 0.0$ & $19 \pm 0.6$ \\
\hline
\end{tabular}

1) Disc containing the oil was placed directly on agar plate

2) Tested at a concentration of $25 \mu \mathrm{L} /$ disc

3) Tested at a concentration of $25 \mu \mathrm{g} / \mathrm{disc}$

4) Values are diameters of clear zone of inhibition $(\mathrm{mm})$ including disc diameter of $8 \mathrm{~mm}$

of silver fir essential oil, however, we previously reported the antiradical activity against DPPH and ABTS radicals of common constituents in essential oils [18]. Limonene exerted strong DPPH radical- (93.1\%) and mild ABTS radical activity (12.4\%), whereas $\beta$-pinene showed medium DPPH radical-scavenging activity (21.4\%) and low activity against ABTS radical (8.8\%). In addition, $\alpha$-pinene exerted very low scavenging for both radicals. In agreement with our data, Wei and Shibamoto [19] showed that limonene exhibited high DPPH radical scavenging ability.

\section{Antibacterial activity}

The silver fir essential oil was tested for antibacterial activity using paper disc method against 6 bacterial strains, including Gram-negative bacteria such as A. baumannii, E. coli, V. parahaemolyticcus; Gram-positive bacteria such as $S$. aureus, $S$. mutans, L. monocytogenes. As can be seen in Table 3, the oil exhibited no antibacterial activity against all the bacterial strains tested except $S$. aureus. The oil $(25 \mu$, $17 \pm 0.1 \mathrm{~mm}$ ) showed about $70 \%$ inhibitory activity of gentamicin $(25 \mu \mathrm{g}, 25 \pm 0.6 \mathrm{~mm})$ against $S$. aureus.

Although the silver oil exerts little antibacterial activity, $a$-pinene had been reported to be active in inhibiting the growth of microorganism [20], and borneol and $p$-cymene were also found to be antibacterial $[21,22]$. Natural active compounds from essential oils are known to possess antimicrobial activity against both pathogen and spoilage microorganism, and Di Pasqua et al. [23] has reported that antimicrobial compounds including limonene exert their activities by changing the lipid profiles, especially a strong decrease of the unsaturated fatty acids, of E.coli, S. aureus, S. ententerica, P. fluorescens, and B. thermosphacta cells. To make clear the mild antimicrobial capacity against $S$. aureus in particular in silver fir oil, the analysis of antimicrobial activities using its main compounds needs to be examined. 
In conclusion, these results indicate that the essential oil of silver fir contain bornyl acetate as a major constituent and has no toxic effect at low concentration for $24 \mathrm{~h}$. The essential oil also shows strong antiradical activities against DPPH and ABTS radicals, while it has little antibacterial properties.

\section{Acknowledgements}

This work was supported by Korea Institute of Industrial Technology Evaluation and Planning (ITEP) and Ministry of Commerce, Industry and Energy (MOCIE) through the Center for Traditional Microorganism Resources (TMR) at Keimyung University, Korea.

\section{Abbreviations}

GC-MS, gas chromatography-mass spectrometry; MTT, 3(4,5-dimethylthiazol-2-yl)-2,5-diphenyl tetrazolium bromide; DPPH, 2,20-diphenylpicrylhydrazyl; ABTS, 2,2'-azino-bis 3-ethyl benzothiazoline-6-sulfonic acid; $\mathrm{RC}_{50}$, concentration required for 50\% reduction; BHT, Butylated Hydroxytoluene; BHA, butylated Hydroxyanisole; FBS, Fetal bovine serum; DMEM, Dulbecco's modified eagle medium; DMSO, dimethyl sulfoxide.

\section{References}

[1] Min, D.B., Li, T.L., and Lee, H.O.: Effects of processing steps on the contents of minor compounds and oxidation of soybean oil. Adv. Exp. Med. Bio., 434, 161-180, 1998.

[2] Carson, C.F., Hammer, K.A., and Riley, T.V.: Melaleuca alternifolia (Tea Tree) oil: a review of antimicrobial and other medicinal properties. Clin. Microbiol. Rev., 19, 50-62, 2006.

[3] Halcón, L. and Milkus, K.: Staphylococcus aureus and wounds: a review of tea tree oil as a promising antimicrobial. Am. J. Infect Control., 32, 402-408, 2004.

[4] Evandri, M.G., Battinelli, L., Daniele, C., Mastrangelo, S., Bolle, P., and Mazzanti, G.: The antimutagenic activity of Lavandula angustifolia (lavender) essential oil in the bacterial reverse mutation assay. Food Chem. Toxicol., 43, 13811387, 2005.

[5] Lis-Balchin, M. and Hart, S.: Studies on the mode of action of the essential oil of lavender (Lavandula angustifolia P. Miller). Phytother. Res., 13, 540-542, 1999.

[6] Ghelardini, C., Galeotti, N., Salvatore, G., and Mazzanti, G.: Local anaesthetic activity of the essential oil of Lavandula angustifolia. Planta Med., 65, 700-703, 1999.

[7] Gamez, M.J., Jimenez, C., Navarro, A., and Zarzuelo, A.: Study of the essential oil of Lavandula dentata L. Pharmazie, 45, 69-70, 1990.

[8] Buchbauer, G., Jirovetz, L., Jaeger, W., Dietrich, H., Plank, C., and Karamat, E.: Aromatherapy: evidence for sedative effects of the essential oil of lavander after inhalation.
Naturforsch C, 46, 1067-1072, 1991.

[9] Umezu, T., Sakata, A., and Ito, H.: Ambulation-promoting effect of peppermint oil and identification of its active constituents. Pharmacol. Biochem. Behav., 69, 383-390, 2001.

[10] Sanders, C., Diego, M., Fernandez, M., Field, T., HernandezReif, M., and Roca, A.: EEG asymmetry responses to lavender and rosemary aromas in adults and infants. Int. J. Neurosci., 112, 1305-1320, 2002.

[11] Choi, H.S., Song, H.S., Ukeda, H., and Sawamura, M.: Radical-scavenging activities of citrus essential oils and their components: detection using 1,1-diphenyl-2-picrylhydrazyl. J. Agric. Food Chem., 48, 4156-4161, 2000.

[12] van de Loosdrecht, A.A., Nennie, E., Ossenkoppele, G.J., Beelen, R.H., and Langenhuijsen, M.M.: Cell mediated cytotoxicity against U 937 cells by human monocytes and macrophages in a modified colorimetric MTT assay. A methodological study. J. Immunol. Meth., 141, 15-22, 1991.

[13] Traub, W.H. and B., Leonhard.: Susceptibility of Moraxella catarrhalis to 21 antimicrobial drugs: validity of current NCCLS criteria for the interpretation of agar disk diffusion antibiograms. Chemotherapy, 43, 159-167, 1997.

[14] Moreno, M.I., Isla, M.I., Sampietro, A.R., and Vattuone, M.A..: Comparison of the free radical-scavenging activity of propolis from several regions of Argentina. J. Ethnophamacol., 71, 109-114, 2000.

[15] Re, R., Pellegrini, N., Proteggente, A., Pannala, A., Yang, M., and Rice-Evans, C.: Antioxidant activity applying an improved ABTS radical cation decolorization assay. Free Radic. Biol. Med., 26, 1231-1237, 1999.

[16] Zeneli, G., Tsitsimpikou, C., Petrakis, P.V., Naxakis, G., Habili, D., and Roussis, V.: Foliar and cortex oleoresin variability of silver fir (Abies alba Mill.) in Albania. $Z$. Naturforsch [C], 56, 531-539, 2001.

[17] Karkabounas, S., Assimakopoulos, D., Malamas, M., Skaltsounis, A.L., Leonce, S., Zelovitis, J., Stefanou, D., and Evangelou, A.: Antiproliferative and anticarcinogenic effects of an aqueous preparation of Abies alba and Viscum se abies, on a L-1210 malignant cell line and tumor-bearing Wistar rat. Anticancer Res., 20, 4391-4395, 2000.

[18] Yang, S.A., Jeon, S.K., Lee, E.J., and Shim, C.H.: Comparative study of the chemical composition and antioxidant activity of six essential oils and their components. Nat. Prod. Res., In press, 2008.

[19] Wei, A. and Shibamoto, T.: Antioxidant activities and volatile constituents of various essential oils. J. Agric. Food Chem., 55, 1737-1742, 2007.

[20] Raman, A., Weir, U., and Bloomfield, S.F.: Antimicrobial effects of tea-tree oil and its major components on Staphylococcus aureus, Staph. epidermidis and Propionibacterium acnes. Lett. Appl. Microbial., 21, 242-245, 1995.

[21] Tabanca, N., Kirirmer, N., Demirci, F., and Baser, K.H.C.: Composition and antimicrobial activity of the essential oils of Micromeria cristata subsp. phyrgia and the enantiomeric distribution of borneol. J. Agric. Food Chem., 49, 43004303, 2001.

[22] Cosentino, S., Tuberoso, C.I.G., Pisano, B., Satta, M., Mascia, V., Arzedi, E., and Palmas, F.: In-vitro antimicrobial 
activity and chemical composition of Sardinian Thymus essential oils. Lett. Appl. Microbiol., 29, 130-135, 1999.

[23] Di Pasqua, R., Betts, G., Hoskins, N., Edwards, M., Ercolini,
D., and Mauriello, G.: Membrane toxicity of antimicrobial compounds from essential oils. J. Agric. Food Chem., 55, 4863-4870, 2007. 